\title{
Chemotherapy and extreme exercise: A potentially dangerous combination
}

\author{
Shivani Jatin Gandhi, Satyajeet Roy \\ Cooper Medical School of Rowan University, USA
}

Received: May 22, 2016

DOI: $10.5430 /$ crim.v3n3p44
Accepted: June 15, $2016 \quad$ Online Published: June 20, 2016

URL: http://dx.doi.org/10.5430/crim.v3n3p44

\begin{abstract}
Acute exertional compartment syndrome of the thighs is extremely rare. It should be considered in patients who present with myalgia and swelling after vigorous exercise. We present a case of a 35-year-old female athlete with breast cancer who had received one cycle of chemotherapy. The patient presented with diffuse myalgias in her thighs after an exercise session. She was diagnosed with chemotherapy induced compartment syndrome of the bilateral thighs with resultant rhabdomyolysis and acute kidney injury. She required continuous venovenous hemodialysis. The patient suffered a cardiac arrest and could not be resuscitated. This case draws attention to the potential myotoxocity of certain chemotherapeutic agents. It also demonstrates acute compartment syndrome as a rare but devastating consequence of extreme physical training associated with certain chemotherapeutic agents. As many of our patients are adopting vigorous exercise routines, it is important for physicians to be aware of acute exertional compartment syndrome, as it necessitates a high degree of clinical suspicion.
\end{abstract}

Key Words: Compartment syndrome, Renal failure, Chemotherapy

\section{INTRODUCTION}

Acute compartment syndrome (ACS) of the thigh is exceedingly rare, especially after exercise. This condition occurs when the intracompartmental pressure overcomes the capillary-filling pressure required to perfuse tissue. When occurring in the muscle, this ultimately leads to tissue ischemia, myonecrosis, rhabdomyolysis, multiple electrolyte derangements and potentially death. The ACS commonly occurs after orthopaedic injury, vascular insult or haemorrhage, crush injuries, or burns; however, ACS can rarely manifest after extreme physical exertion. ${ }^{[1]}$ The definitive management of ACS is emergent release of the fascia. ACS necessitates a high degree of clinical suspicion, as delay in making the diagnosis can be devastating. ${ }^{[2]}$

We discuss the case of a young female athlete with breast can- cer, treated with chemotherapy, who subsequently developed fatal anterior thigh compartment syndrome. The etiology of her compartment syndrome was possibly a culmination of chemotherapy-mediated effects on skeletal muscle, combined with her participation in a competitive and extreme exercise program.

\section{CASE PRESEntation}

A 35-year-old female athlete presented with diffuse myalgias, malaise, weakness and inability to walk for two days. She denied fever, shortness of breath, nausea, or vomiting at the time of presentation. She also denied any history of trauma. Her past medical history was significant for BRCA-positive, triple-negative high-grade invasive ductal carcinoma of the right breast. She underwent one treatment of neoadjuvant dose-dense chemotherapy with doxorubicin, $60 \mathrm{mg} / \mathrm{m}^{2}$ and

*Correspondence: Shivani Jatin Gandhi; Email: gandhi-shivani@ cooperhealth.edu; Address: Cooper Medical School of Rowan University, USA. 
cyclophosphamide, $600 \mathrm{mg} / \mathrm{m}^{2}$ nine days prior to presentation. This was followed by pegfilgrastim $3 \mathrm{mg}$. Of note, the patient was a seasoned athlete and she had participated in an extreme exercise-training program well prior to her breast cancer diagnosis. She attended an exercise training class several days after getting chemotherapy, and prior to symptom onset.

On physical exam, she was tachycardic to 128 beats/min, with blood pressure $118 / 65 \mathrm{mmHg}$, respirations $18 / \mathrm{min}$, and afebrile. She appeared to be in moderate distress, and had bilateral lower extremity edema with tenderness to palpation, mostly in both of her thighs. At the time of presentation, the patient could not ambulate because of severe myalgias.

Her initial bloodwork was significant for elevated serum creatinine of $1.61 \mathrm{mg} / \mathrm{dl}$, metabolic acidosis with anion gap of 27, and creatine kinase of 9,174 U/L. Her urinalysis was notable for brown color, $3+$ blood, elevated urobilinogen and bilirubin. Her arterial blood $\mathrm{pH}$ at this time was 7.22. Her complete blood count was significant for $2.68 \times 10^{3}$ leukocytes $/ \mu \mathrm{l}$, hemoglobin $10.9 \mathrm{~g} / \mathrm{dl}$, platelet count 52,000 cells $/ \mu 1$, with an absolute neutrophil count of 1,610 cells $/ \mu 1$. The rest of her complete metabolic panel was within normal range. She was admitted for suspected rhabdomyolysis. Despite receiving intravenous normal saline at $200 \mathrm{ml} / \mathrm{h}$, she made very little urine. She developed altered mental status and progressive shortness of breath, and she was upgraded to the intensive care unit for emergent intubation. Upon transfer to the ICU, she had a full infectious workup and was started on empiric vancomycin, cefepime, and metronidazole for suspected bacterial sepsis in addition to severe rhabdomyolysis. Blood cultures were obtained and showed growth of Staphyloccocus aureus in one out of two bottles. An influenza and respiratory viral assay including human immunodeficiency virus (HIV) and respiratory syncytial virus (RSV) were negative. In addition, she had a computed tomography scan of the chest, abdomen and pelvis with contrast which had no significant findings other than known breast malignancy.

During the next several hours, the patient's condition rapidly worsened. Repeat bloodwork showed worsening renal injury with profound metabolic acidosis and hyperkalemia refractory to medical therapy with calcium gluconate and bicarbonate. Her arterial $\mathrm{pH}$ had dropped to 7.01, serum $\mathrm{Cr}$ increased to $2.51 \mathrm{mg} / \mathrm{dl}$, and creatine kinase had risen to $34,120 \mathrm{U} / \mathrm{L}$. In addition, her potassium increased to $7 \mathrm{mmol} / \mathrm{L}$. She was therefore started on continuous venovenous hemodialysis (CVVHD).

Her rapid clinical deterioration prompted further evaluation for compartment syndrome. Stryker Intra-Compartmental Pressure Monitor recorded pressures in the right and left anterior thighs as $24 \mathrm{mmHg}$ and $35 \mathrm{mmHg}$, respectively (nor$\mathrm{mal}<10 \mathrm{mmHg}$ ). The patient underwent emergent bilateral anterior thigh fasciotomies at the bedside. Operative findings were significant for dusky, necrotic-appearing muscle, which appeared to bulge through the fascial incisions. Despite CVVHD, the patient's renal failure and hyperkalemia progressed. Her creatine kinase rose to $133,780 \mathrm{U} / \mathrm{L}$, potassium increased to $8.9 \mathrm{mmol} / \mathrm{L}$, and arterial $\mathrm{pH}$ declined to 6.8. Her continuous cardiac monitoring showed progressive widening of the QRS complex, even after several doses of calcium gluconate and bicarbonate infusion. Despite our best efforts, she suffered ventricular fibrillation on the second day of admission. She could not be resuscitated.

A post-mortem examination was significant for diffuse subsegmental pulmonary emboli with associated pulmonary infarction. Furthermore, several of these emboli were associated with bacterial colonies composed of gram positive cocci. Her skeletal muscle did not show evidence of bacterial infection.

\section{Discussion}

ACS of the thigh is uncommon because of the compartments in the thigh are able to accommodate high volumes without significant increases in compartmental pressure. ${ }^{[2]}$ Although extreme exertion can lead to rhabdomyolysis, ACS of the bilateral anterior thighs after exercise is exceedingly rare, and only several case reports exist in the current literature. In reviewing five of these cases, all patients were male and previously physically fit, ${ }^{[2-6]}$ two patients were in the military, ${ }^{[2,4]}$ and one patient died from metabolic derangements. ${ }^{[2]}$ In all cases, patients presented $>24 \mathrm{~h}$ after extreme physical exertion, ${ }^{[2-6]}$ suggesting that patients with this condition may present in a delayed fashion.

Infections, medications, and congenital storage disorders can predispose myocytes to injury, which may increase the risk for the development of ACS. Anti-neoplastic agents can rarely cause myotoxicity. One case report in 2002 implicated high-dose cyclophosphamide as a cause of rhabdomyolysis in a patient undergoing hematopoietic stem-cell transplant. ${ }^{[7]}$ In addition, doxorubicin has been well-known to cause toxicity to cardiac muscle, but animal studies show it may also exert toxicity in skeletal muscle. A study conducted in mice in 2009 showed that with increasing doses of doxorubicin, there was a decrease in the maximum contractile force and velocity with an increase in relaxation time of skeletal muscle, making it more susceptible to fatigue. ${ }^{[8]}$ In addition, Fabris et al. showed in a rat model that skeletal muscle may play an important role in the sequestration of doxorubicin, and direct myocyte injury may occur in response to the development of reactive oxygen species. ${ }^{[9]}$ To our knowledge, this is the first 
reported case of exertional ACS in a female. Furthermore, there are no cases of exertional ACS that occurred following chemotherapy.

When synthesizing this information in relation to our case, it is possible that our patient, who was previously a physically fit and seasoned athlete, may have been predisposed to the development of ACS after receiving dose-dense chemotherapy. Moreover, it is also possible that concurrent bacterial sepsis further predisposed to the development of ACS. Our patient's clinical picture of surgically proven ACS, ongoing rhabdomyolysis, rapidly progressive renal failure and hyperkalemia refractory to renal replacement therapy conclude that her ultimate cause of death was secondary to compartment syndrome, causing hyperkalemia-induced ventricular fibrillation. Furthermore, although she did require mechanical ventilation, she had no evidence of refractory hypoxemia, as her arterial oxygen tension $\left(\mathrm{PaO}_{2}\right)$ remained greater than 100 $\mathrm{mmHg}$. Acute compartment syndrome has been reported in the setting of bacterial sepsis involving bacterial infection of the muscle or pathologically evident bacterial myositis. Our patient did not have such findings, making her case of acute exertional compartment syndrome a rare entity, particularly in the setting of active chemotherapy.

In our day and age, intense exercise training programs continue to gain widespread recognition amongst various populations, some of which may include our patients. In such patients presenting with myalgias, ACS must be on the differential, as a delay in diagnosis can be fatal. Furthermore, clinicians administering certain medications should be especially aware of potential myotoxicity, and they should counsel their patients accordingly.

\section{ACKNOWLEDGements}

We would like to acknowledge the family of our patient, who graciously allowed us to report her interesting case.

\section{CONFLICTS OF INTEREST DISCLOSURE}

The authors have declared no conflicts of interest.

\section{REFERENCES}

[1] Tiwari A, Haq AI, Myint F, et al. Acute compartment syndromes. British Journal of Surgery. 2002; (89): 397-412. PMid:11952578 http://dx.doi.org/10.1046/j.0007-1323.2002.02063.x

[2] Kuklo TR, Tis JE, Moores LK, et al. Fatal rhabdomyolysis with bilateral gluteal, thigh, and leg compartment syndrome after the Army Physical Fitness Test. A case report. Am J Sports Med. 2000; 28(1): 112-6. PMid: 10653554

[3] King TW, Lerman OZ, Carter JJ, et al. Exertional compartment syndrome of the thigh: a rare diagnosis and literature review. J Emerg Med. 2010; 39(2): e93-9. PMid:18597970 http://dx.doi.org/1 $0.1016 / \mathrm{j} \cdot \mathrm{j}$ emermed.2007.10.081

[4] McDonald LS, Mitchell RJ, Deaton TG. Bilateral compartment syndrome of the anterior thigh following functional fitness exercises: a case report. Mil Med. 2012; 177(8): 993-996. PMid:22934383 http://dx.doi.org/10.7205/MILMED-D-11-00417

[5] Leppilahti J, Tervonen O, Herva R, et al. Acute bilateral exerciseinduced medial compartment syndrome of the thigh. Correlation of repeated MRI with clinicopathological findings. Int J Sports Med.
2002; 23(8): 610-5. PMid:12439779 http://dx.doi .org/10.10 $55 / \mathrm{s}-2002-35529$

[6] Wise JJ, Fortin PT. Bilateral, Exercise-induced Thigh Compartment Syndrome Diagnosed as Exertional Rhabdomyolysis: A Case Report and Review of the Literature. Am J Sports Med. 1997; (25): 126-129. PMid:9006707 http://dx.doi.org/10.1177/0363546597025 00125

[7] Shima E, Hino M, Yamane T, et al. Acute rhabdomyolysis following administration of high-dose cyclophosphamide: case report. Ann Hematol. 2002; (81): 55-56. PMid:11807638 http: //dx.doi.org/10.1007/s00277-001-0399-2

[8] van Norren K, van Helvoort A, Argilés JM, et al. Direct effects of doxorubicin on skeletal muscle contribute to fatigue. $\mathrm{Br} \mathrm{J}$ Cancer. 2009; (100): 311-314. PMid:19165199 http://dx.doi.org/10. $1038 / \mathrm{sj} \cdot \mathrm{bjc} .6604858$

[9] Fabris SA, Chenard P, MacLean D. Skeletal muscle as a possible compartment for the sequestering of Doxorubicin following administration. The FASEB Journal. 2012; 26(1_MeetingAbstracts): lb784. 